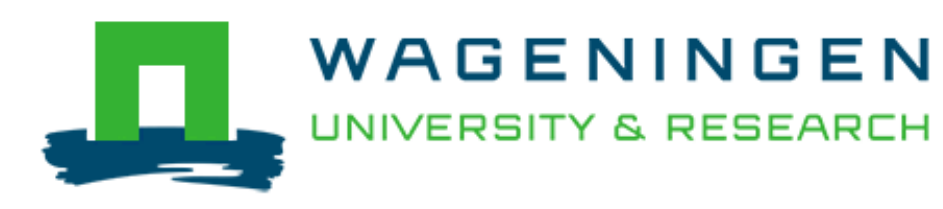

Adaptive delta management: a comparison between the Netherlands and Bangladesh Delta Program

Zevenbergen, C., Khan, S. A., van Alphen, J., Terwisscha van Scheltinga, C., \& Veerbeek, W.

This is a "Post-Print" accepted manuscript, which has been published in "International J ournal of River Basin Management"

This version is distributed under a non-commercial no derivatives Creative Commons (c) (1) $(9)$ reproduction in any medium, provided the original work is properly cited and not used for commercial purposes. Further, the restriction applies that if you remix, transform, or build upon the material, you may not distribute the modified material.

Please cite this publication as follows:

Zevenbergen, C., Khan, S. A., van Alphen, J., Terwisscha van Scheltinga, C., \& Veerbeek, W. (2018). Adaptive delta management: a comparison between the Netherlands and Bangladesh Delta Program. International J ournal of River Basin Management, 16(3), 1-7. DOI: 10.1080/15715124.2018.1433185

You can download the published version at:

https://doi.org/10.1080/15715124.2018.1433185 


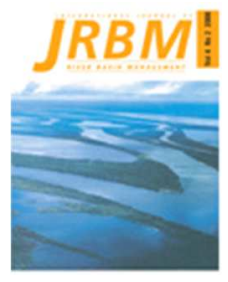

\section{Adaptive Delta Management}

A comparison between the Netherlands and Bangladesh

Delta Program

\begin{tabular}{|r|l|}
\hline Journal: & The International Journal of River Basin Management \\
\hline Manuscript ID & JRBM-2017-0079 \\
\hline Danuscript Type: & Special Issue Paper \\
\hline Complete List of Authors: & $\begin{array}{l}\text { Zevenbergen, Chris; UNESCO-IHE, Flood Resilience Group } \\
\text { Khan, Shah Alam; Bangladesh University of Engineering and Technology, } \\
\text { IWFM } \\
\text { van Alphen, Jos; Staff Deltacommissioner } \\
\text { Terwisscha van Scheltinga, Catherine; Wageningen Universiteit en } \\
\text { Researchcentrum, Alterra } \\
\text { Veerbeek, William; UNESCO-IHE Institute for Water Education }\end{array}$ \\
\hline Keywords: & \multicolumn{2}{|c|}{} \\
\hline
\end{tabular}




\title{
Adaptive Delta Management A comparison between the Netherlands and Bangladesh Delta Program
}

Chris Zevenbergen ${ }^{1}$, Shah Alam Khan ${ }^{2}$, Jos van Alphen ${ }^{3}$, Catharien Terwisscha van Scheltinga ${ }^{4}$, William Veerbeek ${ }^{1}$

\author{
${ }^{1}$ IHE DELFT, THE NETHERLANDS

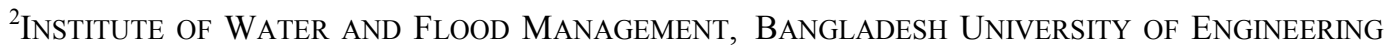 \\ AND TECHNOLOGY, BANGLADESH \\ ${ }^{3}$ StAFF DELTA COMmissioner, THE NETHERLANDS \\ ${ }^{4}$ WAGENINGEN ENVIRONMENTAL RESEARCH (ALTERRA), THE NETHERLANDS
}

\begin{abstract}
In the Netherlands, the central government, water authorities, provinces and municipalities are working together on a new Delta Program on Flood Risk Management and Fresh Water Supply (DP). Its primary goal is to protect the Netherlands against floods and ensure the availability of fresh water, now and for future generations. The DP has developed a new, adaptive management concept: the Adaptive Delta Management (ADM) approach. ADM is defined as "a smart and intelligent way of taking account of uncertainties and dependencies in decision-making on Delta Management with a view to reducing the risk of overspending or underinvestment". Important features of DP are: (i) involving multiple stakeholders in a joint decision making process to enhance ownership, legitimacy and feasibility; (ii) taking a risk-based perspective, (iii) adopting a flexible approach in possible strategies by valuing flexibility with regard to the timing of implementation; and (iv) inter-linking various investment agendas and looking for opportunities for mainstreaming with planned investments.

Along similar lines a Bangladesh Delta Plan 2100 (BDP 2100) is being devised to achieve long term sustainable socio-economic development and provide safety in the face of disasters through adaptive water governance in Bangladesh. It embodies a holistic, integrated vision, adaptive strategies and a long-term investment agenda for the Bangladesh Delta. The Plan is scheduled to be finalized in 2017. ADM is not an approach that can be transferred easily from one country to another as it demands a fundamental change in institutional capacity at multiple levels including new knowledge and skills, relationships and policy frameworks, and, hence, depends on the local socio economic characteristics, culture and governance.. This paper explores the challenges and opportunities for successful formulation and implementation of BDP 2100.
\end{abstract}

Key words: adaptive delta management, multi-level governance, flood risk management 


\section{INTRODUCTION}

The challenges for flood risk and fresh water management strategies of river basins and deltas are manifold, as water safety issues interact with a wide range of environmental and socio-economic sectors including health, agriculture, biodiversity, industry, navigation and tourism. In addition, in trans-boundary river basins differences in legal frameworks, historical and cultural backgrounds add to the complexity (Timmerman and Langaas, 2005). Management of river basins requires a flexible and adaptive programmed approach including the supporting capabilities such as integrated and adaptive policy frameworks and the institutional capacity at multiple levels and across different jurisdictions and countries to exploit these interactions, create synergies and avoid undesired outcomes (Huntjens et al., 2011; Rijke et al., 2012). The flexibility depends on the capacity of the decision makers to learn from the arrival of new information and their willingness and ability to revise investment decisions based upon that learning (e.g. Gersonius et al. (2010))

Based upon the principles of adaptive management (AM) and started in 2003, the TE2100 project is probably one of the first to propose an adaptive approach to manage flood risk. The project aims to protect London and the Thames Estuary from tidal flooding and proposes a series of possible interventions until 2100 that can cope with large ranges of change if needed (Reeder and Ranger, 2009). This approach has demonstrated to be instrumental for decision makers to understand the suite of options open to them and how they can be combined into 'decision pathways' that create a portfolio of measures through the century (Reeder et Ranger, 2009). Inspired by TE2100, the Dutch Delta Program adopted this adaptive approach (referred to as Adaptive Delta Management $(\mathrm{ADM}))$ to deal with the difficulties of anticipating climate change and socio-economic developments in protecting the Netherlands against flooding and to safeguard future fresh water supply in 2010 (Ministry of Transport, Public works and Water Management, 2010). In the first years (2010-2014) the Delta Program has delivered a coherent set of five major 'Delta decisions' and six regional adaptive strategies (Ministry of Infrastructure and Environment, 2014) In the coming decades the emphasis will shift towards further elaboration of the adaptive strategies and implementation of the measures.

Along similar lines a Bangladesh Delta Plan 2100 (BDP 2100) is being devised to achieve long term sustainable socio-economic development and provide safety in the face of disasters in Bangladesh through Adaptive Delta Management (ADM). With the 'delta vision' to ensure long term water and food security, economic growth and environmental sustainability while effectively coping with natural disasters, climate change and other delta issues through robust, adaptive and integrated strategies, and equitable water governance, and six delta plan goals linked with the 'Sustainable Development Goals', the plan foresees a paradigm shift in implementation of the plan through ADM. Following the ADM principles, analytical frameworks, delta scenarios, strategy framework and adaptive pathways have been developed to achieve these goals by dividing the country into six predominant 'hotspots' or representative planning units. The plan includes an investment plan and an implementation framework which envisions establishment of a 'Delta Commission' and a 'Delta Fund'. BDP2100 aims to built upon the first lessons learned from the Delta Program in the Netherlands, but is adjusted to the Bangladeshi conditions and policy frameworks where it will be integrated into the 5 year economic development plans in which provide a framework to ensure the integrative character of the plan as well as the implementation of the plan. The development of BDP 2100 is scheduled to be completed in 2017. The relevance of ADM for developing countries lies in the possibility it offers to develop adaptive and integrated strategies logically underpinning investment decisions in domains characterized by significant uncertainties about the future, such as water safety and freshwater supply (Bloemen, 2014). 
ADM is not an approach that can be transferred easily from one country to another as it employs a relative strict methodology and given the long term scope, a consistent policy for the short- and long term. Hence, it demands a fundamental change in institutional capacity at multiple levels including new knowledge and skills, relationships and policy frameworks and a meaningful inclusive planning approach. Socio-economic conditions, culture and governance are important factors to be considered in this transformation process. This paper attempts to identify the challenges and opportunities for successful formulation and implementation of BDP 2100 based on an intercomparision of the geographical and institutional context of Bangladesh and The Netherlands.

\section{THE PRINCIPLES OF ADAPTIVE MANAGEMENT}

Adaptive management has emerged in the US since the 1990s to support natural resource management policy as a response to short-comings of the 'traditional' approaches to manage natural resources. It is defined as a systematic process of learning from the outcomes of management actions, accommodating change, and thereby improving management (Gunderson, 1999). Hence, it entails a systematic and structured process for continuing improving management policies and practices acknowledging our limited understanding of natural system's behavior.

Adaptive management is considered as an effective strategy if (i) uncertainty is acknowledged and 'information gaps' are identified, and thus when learning is needed to achieve certain management goals, (ii) there are good prospects for learning and experimenting in order to narrow down information gaps over time, and (iii) the socio-economic and physical changes warrant to adjust management directions (interventions) as a consequence of lessons learnt (Doremus et al., 2011). It is not surprising that there is a growing interest in adaptive management in many river restoration efforts and more recently in flood management programs. Well know examples of the first category are typically from the US including the Mississppi River Basin, the Colarado river and Colombia River Basin. Examples of the second category comprise the previously mentioned Thames Estuary project (TE2100) and the Dutch and Bangladesh Delta Program.

In spite of these promising prospects several attempts to develop and implement adaptive management have failed due to institutional constraints, a lack of stable (long-term) funding and resources for information gathering and monitoring, reluctance of decision makers to admit and embrace uncertainties in making policy choices, and lack of leadership in implementation (Lee, 1999; Walter, 2007). To overcome these challenges, three enabling elements are deemed necessary to successfully implement adaptive management in practice: (i) a system approach, (ii) participatory decision making and (iii) learning and experimentation (Huitema et al., 2009; Berkes, 2009, Van Herk, 2014). In addition, continuity in implementation has to be provided by institutional arrangements on leadership, funding and legal aspects (Van Alphen, 2013)

\section{BANGLADESH: GEOGRAPHICAL AND INSTITUTIONAL CONTEXT}

Bangladesh is located at the junction of the Ganges, Brahmaputra and Meghna rivers in the world's largest river delta. About $93 \%$ of the combined river basins are located outside of the country. The tropical climate of Bangladesh is monsoon driven, with about $80 \%$ of the annual rainfall occurring between June and September. The resulting seasonal cross-border and domestic 
runoff is therefore tremendous and far exceeds the drainage capacity of channels and rivers. Monsoon driven flooding inundates about $20 \%$ of the country annually (Mirza et al., 2002), while about $90 \%$ of the country is prone to extreme flood events that apart from riverine flooding also include flash floods, storm surges as well as pluvial flooding which is especially problematic in peri-urban and urban areas. (e.g. Brammer, 2004). Other water related challenges are river bank erosion, storm surges and salinization in the coastal region, droughts, pollution of surface water, arsenic contamination of ground water, With a population of about 156 million and one of the highest population densities, these water challenges have a big impact on the lives and livelihoods of the inhabitants. Many of these issues are exemplified by the capital Dhaka, which is one of the world's fastest growing megacities with an annual growth rate exceeding 4\%. The extensive ruralurban migration that drives this growth is reflected in Dhaka's unplanned urbanisation, which together with a poor urban drainage system, result in severe water logging due to drainage congestion by solid waste as well as encroachment of rivers and illegal land-filling of surface water bodies (Khan, 2006; Ahmed \& Ahmed, 2012).

Since 1950, Bangladesh has been facing 16 catastrophic floods (Ahmed, 2014). After the particularly devastating flood of 1988 which submerged more than 2/3rd of the country, the Flood Action Plan (FAP) was developed. The Government of Bangladesh (GOB)-initiated plan aimed at fully embanking major rivers in Bangladesh (World Bank, 1989) including the Ganges, Jamuna Bramahputra and the Meghna. Apart from the protection of urban areas, the plan aimed at ensuring food security by protecting and managing crop fields and polders. While the FAP might have decreased the country's vulnerability to flood hazard, the initially estimated at USD 155 billion plan proved to be too ambitious. Apart from lack of funding, it was doubtful if the economic returns from protecting the agricultural lands would outweigh the estimated costs. Furthermore, the FAP was facing strong opposition from the civil society due to the top-down institutional hegemony associated to its formulation and implementation as well as social and environmental concerns (Brammer, 2010). This led to a comprehensive review of the Bangladesh national water policy, which resulted in the National Water Management Plan (WARPO, 2001) emphasising small-scale flood proofing measures. Since the programme was not included in the 5year development plans which provide the cornerstones of Bangladesh policy, almost no proposed measures were actually implemented. More successful were measures related to cyclonic storm surge flooding in the coastal area. After the disastrous floods of 1970 (500.000 fatalities) and 1991 (135.000 fatalities) a large early warning and shelter program was implemented in the coastal polders. As a result the 2007 cyclone Sidr resulted in only 3400 fatalities, a reduction of about $99 \%$. Still Bangladesh remains vulnerable to flooding. With steady economic growth rates of $6 \%$ damage to assets, transport infrastructure and power supply, as well as the functioning of the capital Dhaka become relevant, as was illustrated during the severe floods in 2004 and 2007. It should be noted here that the prevailing 'protection with embankment' approach has created longterm problems such as de-linking river-floodplain connectivity (impact on fisheries), pumped drainage approach creating urban flooding,.

Over the past 40 years The Netherlands has a longstanding involvement with the Bangladeshi water sector through its development cooperation. The development of the polders along the coast, the creation of the water management organisations by the water-users and the increased number of rural people with drinking water supply and sanitation are examples of the Dutch support. However, as Bangladesh is moving fast towards a mid-income country, the development cooperation will be phasing out in future. Various government and semi-government agencies are involved in urban land use, land and water management in Bangladesh. The existing institutional setting, with e.g. 13 ministries affiliated with water management, makes it difficult to deliver timely responses to the growing needs of a rapidly expanding urban population. There are many 
challenges in the rapidly growing cities of Bangladesh. For example, there have been several master plans for urban development for Dhaka. The actual development never followed these plans completely. The deviation was the result of failure to implement/execute the plans - not only because of the lack of finance or realistic investment plans, but also because of the lack of institutional accountability for implementation, and the lack of political will. Coordination between the agencies and some degree of decentralization is deemed necessary (Zaman et al., 2010). In this context, strengthening of land management policies through coordination between the various related agencies and some degree of delegation of authority is considered to be conditional to meet the urban development situation (Zaman et al., 2010).

\section{The Dutch Delta Program}

In the Netherlands, the national government, water boards, provinces and municipalities are working together on a new Delta Program on Flood Risk Management and Fresh Water Supply (DP). It comprises a cohesive set of projects (measures) for the short term (up to and including 2028), but also looks ahead to the medium term (up to 2050). The rationale behind this long term approach is three-fold: (i) investments in land use and water related infrastructure (dams, dykes, sluices, storm surge barriers) have typical life times of many decades to a century or even more. In addition, they determine the future prospect of spatial planning and land use. With these life times the potential impact of climate change may become serious and has to be considered in the design and decision making. (ii) experiences with other major water management programs in the Netherlands shows that the implementation of these programs takes many decades. Therefore, to be prepared for climate change in 2050 the preparations should start now. (iii) with implementation times of many decades it is inevitable that new knowledge and new techniques have to be absorbed and that political priorities change. For a successful implementation a common vision, as a framework for policy goals, is necessary, with flexible routes to achieve, no "blue prints". This insight has prompted the DP to develop a new, adaptive management strategy: the Adaptive Delta Management (ADM) approach (Isoard and Winograd, 2013). The Delta Program defines ADM as " $a$ smart and intelligent way of taking account of uncertainties and dependencies in decision-making on Delta Management with a view to reducing the risk of overspending or underinvestment" (Van Alphen, 2013) It is pivotal in the Delta Program that, starting from a common vision, decision-making on flood risk management measures needs to take account of a medium to long-term planning horizon as (unforeseen) future developments could influence the efficiency of these measures, for example in terms of use of space. Some developments may lead to higher costs, e.g. building-over spaces that could later have been more usefully deployed for water storage or water discharge. While other developments could lead to cost reductions, e.g. combining river widening with the replacement of sluices approaching endof-life. Therefore, decisions on short-term measures should be taken in such a way as to avoid the unnecessary mounting of long-term costs, while agreements should be made on actions that could be linked efficiently. ADM aims to ensure that any short- to medium-term adaptation decision is set within a framework that will not be maladaptive, if future developments (e.g. sea level rise) are different from what is currently predicted to be 'the most probable' (Reeder and Ranger, 2011). A new element of ADM compared to AM is the inclusion of Adaptation Tipping Points (ATPs). ATPs are defined here as points where the magnitude of change due to external pressures such as sea level rise or peak discharges is such that the current strategy will no longer be able to meet the objectives and thus the measure are no longer adequate. (Kwadijk et al., 2010). Combining the defined ATPs with climate change scenarios provide information about the need for additional measures. The ATP analysis can, therefore, help to develop Adaptation Pathways (Haasnoot et al., 2012; Haasnoot et al., 2013). These refer to coherent sequences of measures and potential options, 
which may be triggered before an ATP occurs. Adaptation Pathways provide insight into the options, lock-ins and path dependencies and introduces the flexibility to adapt to a wide range of future developments. Hence, Adaptation Pathways aim to be particularly useful in the context of long-term planning and to link the implementation of strategies for flood risk management with other investment agendas (Rhee, 2012).

The objective of ADM is to provide a transparent and structured management process, which takes uncertainty into account in investment decisions of future developments. The Delta Program defines the following objectives and means to operationalize ADM (Van Alphen, 2013):

1. taking a systems approach that takes into account various spatial scales, linkages between main and regional water systems, upstream-downstream relations, and interaction between flood risk management and fresh water supply;

2. involving multiple stakeholders in a joint decision making process to enhance ownership, legitimacy and feasibility;

3. adopting a scenario-based approach in the possible strategies by valuing flexibility with regard to the timing of implementation. allowing to switch from strategies through adaptation pathways;

4. inter-linking various investment agendas and looking for opportunities for mainstreaming with planned investments in e.g. urban development or nature restoration.

The next step will be the application of ADM in the implementation phase of the program and subsequently to monitor external drivers (climate change), regularly evaluate the effectiveness of associated measures and determine whether acceleration (deceleration) or a transition to another strategy is necessary. The emphasis will therefore shift from the development of adaptive strategies towards their implementation and management in practice. This implies that ADM is still in its early stage of development and its effectiveness needs to be proven in the implementation phase.

\section{The Bangladesh Delta Plan}

Through a partnership of the GOB and the Embassy of the Kingdom of the Netherlands (EKN), a consortium of Bangladeshi and Dutch knowledge institutions, private and public sector representatives has been appointed to develop a Bangladesh Delta Plan (BDP) that should address the many water issues in Bangladesh and provide a feasible future strategy. Learning from past initiatives, the plan has to accommodate for future uncertainties and should be mainstreamed into the 5-year development plans to ensure adoption and implementation. A key issue in the plan is to develop an operational adaptive planning framework that can accommodate several future strategies, thus providing the required flexibility to shift between pathways when external conditions dictate change. Such an approach should avoid the development of a 'top heavy' plan that depends on a unique set of conditions to be implemented (e.g. funding). Currently, the consortium is opting for an Adaptive Delta Management-methodology including Adaption Tipping Points and Pathways. While by now this methodology is well established (e.g. Kwadijk et al., 2010), application in a developing country is not necessarily straightforward and might require modification of some of the procedures.

\section{DISCUSSION AND CONCLUSIONS}


In this final section the four objectives of ADM have been used to explore the applicability of the adaptive approach to the context of Bangladesh.

\section{Taking a systems approach that takes into account various spatial scales} In the DP the Dutch delta ${ }^{1}$ is conceived as a coherent set of interconnected subsystems of rivers, lakes, estuaries and coastal areas: interventions implemented in one subsystem will impact or put restrictions on other subsystems. In order to set a baseline and to monitor changes, an understanding of the system's behaviour is considered a pre-requisite for ADM. The DP has adopted a hierarchy in decision making: policy frameworks on national level (such as on flood protection standards), determine decisions taken at a regional scale). The Delta model ${ }^{2}$ was used to enable comprehensive analysis of the interaction between different water systems in times of high and low water. The need to consider the Ganges-Brahmaputra delta as one complex system, which needs to be managed in an integrative way, is widely accepted amongst the water authorities in Bangladesh. The Ganges-Brahmaputra Delta is the world's largest delta and is situated in the tropical wet climate zone with the occurrence of frequent cyclones. People living on the delta have adapted to the occurrence of frequent flooding. One of the greatest challenges people living on this delta may face in the coming years are the impacts of rising sea levels caused by subsidence in the region and climate change. Compared to the Dutch delta, however, our understanding of the actual functioning of this complex delta system is still limited which implies that the consequences of interventions in the water system such as river channelling to it's overall functioning, are still difficult to assess. Another complicating factor is that $93 \%$ of the river basin is outside Bangladesh which limits the level of control over the system.

The population density of the Dutch delta and Ganges-Brahmaputra delta are in the same order of magnitude and both deltas are to a great extent cultivated. Despite these similarities, there are also significant differences between the two. In particular, in the Dutch delta, the rivers are relatively small and less dynamic, have been trained, and coastal protection engineering has stabilized the coastline, whereas in the Ganges-Brahmaputra delta the rivers are huge and coastlines are constraint only to a limited extent. The Ganges-Brahmaputra delta is therefore more dynamic and variable, and less impacted by human interventions. The development of new river control structures, global sea-level rise, and climate change will likely have a large impact on these dynamics in the near future and projections of these changes are surrounded by large uncertainties. This also accounts for the projected socio-economic changes in this delta. It is tempting to postulate that given these differences in dynamics and associated uncertainties between both deltas, the application of the ADM approach to the context of Bangladesh will require new methodologies and tools as the current ones have been developed for a different system's scale, volatility and uncertainty.

\section{Involving multiple stakeholders in joint a decision making process to enhance legitimacy and feasibility \\ In the Netherlands, the design, planning and implementation are performed in close collaboration with other administrations and stakeholders. The process of decision-making governs the development of new knowledge. Joint fact-finding is applied to include the knowledge and expertise of all parties involved. In addition, this approach improves trust and acceptance of the measures (Verkerk et al., 2014) and enhances ownership for the implementation. In Bangladesh, a}

\footnotetext{
${ }^{1}$ Dutch delta or Rhine-Meuse delta comprises the delta of the rivers Rhine and Meuse

2 Delta model: " $a$ model for the Delta Program in order to be able to carry out the underlying calculations" (Deltacommissaris, 2012)
} 
top-down orientated delivery of policies, little coordination and collaboration between the different water authorities combined with limited financial resources and absence of inclusive and realistic planning are amongst others factors that hampers the transition to integrated water management in Bangladesh. It is increasingly recognized that a fundamental change in institutional capacity at multiple levels including new knowledge and skills, relationships and policy frameworks is needed. This is certainly a pressing need at local stakeholder level as the capacity and resource availability to engage in these collaborations are very limited. Yet knowledge development is often highly centralized and exclusive; knowledge is conceived as a commodity and sharing is not common practise. This is hampering the dissemination and use of common knowledge foundation across stakeholders. The BDP process aims to create the incentives for collaboration between sectors and intergovernmental cooperation, and thus may contribute to the overall quality of governance and institutional arrangements.

Adopting a flexible approach in the possible strategies by valuing flexibility with regard to the timing of implementation.

"ADM requires well established policy goals, a subsequent normative framework and a set of corresponding indicators and thresholds to evaluate the performance of many components in the water system." (van Alphen, 2013). In Bangladesh, many of these thresholds have been already exceeded (e.g. urban drainage standards) or are outdated or absent (e.g. flood risk standards). This means that an alternative appraisal framework needs to be developed (BDP, 2014). This certainly applies to the perspectives of adopting a flexible approach in the possible strategies of ADM. A flexible approach allows to switch from strategies through adaptation tipping points (ATP), and adaptation pathways, keeping options open, and requires continuous monitoring and evaluation. It still needs to be seen whether such a flexible approach of ADM can be effectively applied into practice in both countries as within the time scales of decision making detection of climate change is a difficult task. For tipping points related to slowly changing conditions it may work, but for those conditions that are effected by extreme events such an approach runs the risk of being too late (Haasnoot et al., 2013). Due to the fact the implementation of actual measures is still very limited in Bangladesh, marginal experience in monitoring and adapting currently exist in the domain of water related infrastructure. This needs to be setup from scratch including the technology, procedures and institutional embedding. Up till now there has been little room for experimentation in Bangladesh (as opposed to the situation on the Netherlands). Exception is for instance tidal river management (controlled flooding to allow land accretion inside the polder and naturally dredge deposited sediment in the river), where local knowledge in collaboration with land owners, farmers and implementing agencies has been mainstreamed to create a regional policy.

\section{Inter-linking various investment agendas and looking for opportunities for mainstreaming} with planned investments

ADM calls for the development of adaptive and integrated strategies, which are logically based on investment decisions in domains characterized by significant uncertainties about the future, such as water security and freshwater supply (Bloemen, 2014). Financing and advising organizations such as the OECD and the World Bank (e.g. WDR2014) are becoming more and more interested in $\mathrm{ADM}$ as this approach may provide incentives for finding external financing of (water-related investment) projects in developing countries. Hence, the availability of stable long-term (public) funding and resources are considered conditional for ADM. However, basic infrastructure, such as drainage systems and flood defenses provide a direct investment opportunity to attract other funding opportunities and/or private investment if it can be linked to other benefits such as a broader upgrading or redevelopment strategy for an area. As it demands a long-term scope ADM has the potential to help to merge various investment agendas and create added value by 
mainstreaming with planned investments. This trajectory requires to involve multiple stakeholders in joint decision making process to enhance legitimacy and feasibility. It needs to be seen whether the prospects of 'multiple functions and synergistic mainstreaming' will be feasible and thus realistic for wide spread uptake as they substantially differ from the current practice of conventional single-purpose project developments in both countries.

In conclusion, $\mathrm{ADM}$ has up till now been developed and applied in a relatively stable context of the Dutch delta, facing only a limited range of long term uncertainties. To successfully apply the approach in a more volatile and complex context of a developing country requires modification of the method, and tools as well as a 'learning by doing'-mentality to gain experience and apply the necessary pragmatism to implement an effective and result driven policy framework that both embraces uncertainties and manages to adopt a long term horizon.

\section{REFERENCES}

Ahmed, B., \& Ahmed, R. (2012) Modeling Urban Land Cover Growth Dynamics Using MultiTemporal Satellite Images: A Case Study of Dhaka, Bangladesh. ISPRS International Journal of Geo-Information, 1(1), 3-31.

Berkes, F. (2009) Evolution of co-management: Role of knowledge generation, bridging organizations and social learning. Journal of Environmental Management 90, 1692-1702.

Bloemen, P. (2014) Personal communication

Brammer, H. (2004) Can Bangladesh be protected from floods? University Press, Dhaka, Bangladesh

Brammer, H. (2010) After the Bangladesh Flood Action Plan: looking to the future. Environmental Hazards, 9(1), 118-130.

Chaudhry, M.H. (1993) Open-channel flow. Prentice Hall, Eaglewood Cliffs, New Jersey.

Gersonius B (2012) The resilience approach to climate adaptation applied for flood risk. PhDthesis. UNESCO-IHE and Tu Delft. ISBN 978-0-415-62485-5.

Graves, A.L. and Gooch, R.S. (1986) "Central Arizona Project start up." Proceedings of the Water Forum '86: World Water Issues in Evolution. ASCE, New York, N.Y., Vol. 1, 546-551.

Haasnoot M., Kwakkel J.H., Walker W.E., Ter Maat J. (2013) Dynamic adaptive policy pathways: A method for crafting robust decisions for a deeply uncertain world. Global Environmental Change. doi: 10.1016/j.gloenvcha.2012.12.006

Haasnoot M, Middelkoop H, Offermans A, (2012) Exploring pathways for sustainable water management in river deltas in a changing environment. Climatic Change 115:795-819. doi: 10.1007/s10584-012- 0444-2

Huntjens, P., Pahl-Wostl, C., Rihoux, B., Schlüter, M., Flachner, Z., Neto, S., Koskova, R., Dickens, C., Nabide Kiti, I. (2011) Adaptive water management and policy learning in a changing climate: a formal comparative analysis of eight water management regimes in Europe, Africa and Asia. Environmental Policy and Governance 21, 145-163.

Huitema, D., E. Mostert, W. Egas, S. Moellenkamp, C. Pahl-Wostl, and R. Yalcin. (2009) Adaptive water governance: assessing the institutional prescriptions of adaptive (co)management from a governance perspective and defining a research agenda. Ecology and Society 14(1): 26. [online] URL: http://www. ecologyandsociety.org/vol14/iss1/art26

Isoard, S. and Winograd, M. (2013) Adaptation in Europe. Addressing risks and opportunities from climatechange in the context of socio-economic developments . EEA-R--3/2013, $136 \mathrm{pp}$, European Environment Agency, Copenhagen (Denmark) 
Karkanis, S.A., Magoulas, G.D. and Karras, D.A. (2005) "Neural Network based textural labeling of images in multimedia applications", http://citeseer.nj.nec.com/548073.html.

Khan, M.S.A. (2006) "Stormwater flooding in Dhaka city: causes and management", Journal of Hydrology and Meteorology, Nepal, Vol. 3, No. 1, pp. 77-85.

Kwadijk J.C.J., Haasnoot M., Mulder J.P.M., (2010) Using adaptation tipping points to prepare for climate change and sea level rise: a case study in the Netherlands. Wiley Interdisciplinary Reviews: Climate Change 1:729-740. doi: 10.1002/wcc.64

Ministry of Transport, Public Works and Water Management, (2010) The 2011 Delta Programme "Working on the Delta, investing in a safe and attractive Netherlands, now and in the future. The Hague, The Netherlands.

Ministry of Infrastructure and Environment (2014) The 2015 Delta Programme "Decisions to keep the Netherlands safe and liveable. The Hague, The Netherlands.

Rhee G van (2012) Handreiking Adaptief Deltamanagement [Guidelines Adaptive Delta Management]. The Hague

Reeder, T. and N. Ranger (2009) How do you adapt in an uncertain world? Lessons from the Thames Estuary 2100. project.World Resources Report, Washington DC. Available online at http://www.worldresourcesrepor org.

Rijke, J., van Herk, S., Zevenbergen, C., Ashley, R. (2012) Room for the River: Delivering integrated river basin management in the Netherlands. International Journal of River Basin Management 10, 369-382.

Timmerman, J. and Langaas, S. (2005) Water information: what is it good for? - The use of information in transboundary water management Regional Environmental Change, Vol 5, pp 177-187.

Van Alphen, J. (2013) The Delta Program in the Netherlands, a long term perspective on flood risk management. In: Chavosian, A \& K. Takeuchi (eds.) Floods from risk to opportunity, IAHS publication 357, Proc. of the $5^{\text {th }}$ international Conference of Flood Management, Tokyo, 2011. 13-20.

Van Herk, S. (2014) Delivering integrated flood risk management; governance of collaboration, learning and adaptation. TU Delft \& UNESCO-IHE PhD thesis, CRC Press/Balkema, Leiden. ISBN 978-1-138-02632-2

Verkerk, J., and van Buuren, M.W. (2013) Integrated Water Resources Management in the Netherlands. Historical Trends and Current Practices in the Governance of Integration. International Journal of Water Governance 1, 427-452 427, DOI: 10.7564/13-IJWG6

Verkerk, J., Van Buuren, A., Teisman, G. (2014) Resultaten survey Deltaprogramma, Delta governance. Erasmus Universiteit, Januari 2014.

WARPO, (2001) National Water Management Plan, Vol.2: Main Report, Water Resources Planning organization, Ministry of Water Resources, Government of the People ${ }^{\text {ee }}$ s Republic of Bangladesh

Wu, B., Molinas, A. and Yang, C.T. (1996) "Sediment Transport in the Yellow River." Journal of Hydraulic Engineering, ASCE, 122( 5), 237-244.

Zaman, A.K.M., Tariqul Alam, K , Islam, J. (2010) Urbanization in Bangladesh: Present Status and Policy Implications ASA University Review, Vol. 4 No. 2. 